Majalah Biomorfologi

Volume 30 Number 2, July 2020

p.ISSN:0215-8833, e.ISSN: 2716-0920, DOI:10.20473/mbiom.v30i2.2020.39-44

\title{
The similar changes of glucose levels before and after moderate intensity exercise acutely in the morning and evening
}

\author{
Ronik Harsono Kamal ${ }^{1}\left({ }^{(0}\right.$, Kristanti Wanito Wigati ${ }^{2 *}\left(\mathbb{D}\right.$, Achmad Lefi $^{3}$ \\ ${ }^{1}$ Medical Program, Faculty of Medicine, Universitas Airlangga, Surabaya, Indonesia, ${ }^{2}$ Department of \\ Physiology and Biochemistry, Faculty of Medicine, Universitas Airlangga, Surabaya, Indonesia, ${ }^{3}$ Department \\ of Cardiology and Vascular Medicine, Dr. Soetomo General Academic Hospital, Surabaya, Indonesia
}

\begin{tabular}{|c|c|}
\hline Article Info & ABSTRACT \\
\hline $\begin{array}{l}\text { Article history: } \\
\text { Received Jan 25, } 2020 \\
\text { Revised Jun 1, } 2020 \\
\text { Accepted Jun 15, } 2020 \\
\text { Published Jul 1, } 2020\end{array}$ & $\begin{array}{l}\text { Background: There is a lot of research on the importance of } \\
\text { exercise but studies on the effective time of exercise regarding } \\
\text { regulation of blood glucose levels are not clearly known. Objective: } \\
\text { This study aimed to determine the comparison of changes in blood } \\
\text { glucose levels before and after moderate intensity physical exercise } \\
\text { in the morning and evening. Materials and Methods: Healthy men }\end{array}$ \\
\hline $\begin{array}{l}\text { Keywords: } \\
\text { Circadian rhythms } \\
\text { Exercise } \\
\text { Glucose } \\
\text { Moderate intensity }\end{array}$ & $\begin{array}{l}18.5-22.9 \mathrm{~kg} / \mathrm{m} 2 \text { (normal Asia Pacific), participating in the morning } \\
(8.00 \mathrm{am}) \text { or evening group }(20.00 \mathrm{pm}) \text { are asked to do moderate } \\
\text { intensity physical exercise }(55-70 \% \text { of maximum heart rate) using } \\
\text { ergocycle for a total of } 40 \text { minutes. Blood glucose levels } 2 \text { hours post } \\
\text { prandial capillaries were taken before exercise and blood glucose } \\
\text { levels after exercise were taken acutely. Results: The mean decrease } \\
\text { in blood glucose levels in the morning group was } \pm 8.353 \pm 9.16 \\
\text { mg/dL and in the evening group was } \pm 6.294 \pm 10.10 \mathrm{mg} / \mathrm{dL} \text {. Blood } \\
\text { glucose levels decreased significantly for the morning group } \\
(\mathrm{p}=0.002) \text { and the evening group }(\mathrm{p}=0.021) \text {. The comparison of } \\
\text { changes in blood glucose levels between the morning and evening } \\
\text { groups was not significant ( } \mathrm{p}=0.538) \text {. Conclusion: There was no } \\
\text { difference between morning or evening exercise related to changes } \\
\text { in blood glucose levels. }\end{array}$ \\
\hline
\end{tabular}

\begin{abstract}
Background: There is a lot of research on the importance of This sudy ained to detere mine the comparison of changes in blood glucose levels before and after moderate intensity physical exercise in the morning and evening. Materials and Methods: Healthy men $(n=34)$, age between 17-22 years, Body Mass Index (BMI) between $18.5-22.9 \mathrm{~kg} / \mathrm{m} 2$ (normal Asia Pacific), participating in the morning $(8.00 \mathrm{am})$ or evening group $(20.00 \mathrm{pm})$ are asked to do moderate intensity physical exercise (55-70\% of maximum heart rate) using ergocycle for a total of 40 minutes. Blood glucose levels 2 hours post prandial capillaries were taken before exercise and blood glucose levels after exercise were taken acutely. Results: The mean decrease in blood glucose levels in the morning group was $\pm 8.353 \pm 9.16$ $\mathrm{mg} / \mathrm{dL}$ and in the evening group was $\pm 6.294 \pm 10.10 \mathrm{mg} / \mathrm{dL}$. Blood glucose levels decreased significantly for the morning group $(\mathrm{p}=0.002)$ and the evening group $(\mathrm{p}=0.021)$. The comparison of changes in blood glucose levels between the morning and evening groups was not significant $(\mathrm{p}=0.538)$. Conclusion: There was no in blood glucose levels.
\end{abstract}

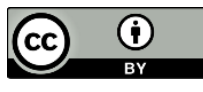

\section{Corresponding Author:}

Kristanti Wanito Wigati

Department of Physiology and Biochemistry, Faculty of Medicine, Universitas Airlangga

Jl. Mayjen. Prof. Moestopo no. 47, Surabaya 60131, East Java, Indonesia

kristanti@fk.unair.ac.id

\section{BACKGROUND}

Exercise is a physical activity that is planned, structured, repeated, directed and aimed to improve the fitness of one's body (WHO, 2018). Often forgotten, lack of physical activity has been identified as the fourth risk factor for global deaths, which is $6 \%$ of global deaths or around 3.2 million deaths in the world (WHO, 2018). Determining the right time to exercise is considered as a controversial thing in society due to daily activities that is inconvenient in regards to the time for exercising.

Several studies have discussed the impacts of exercise on the body occuring at different time and moments. A research was conducted by Zheng et al. (2020) stated that type 2 diabetic patients who carried out an acute moderate intensity aerobic exercise in the morning before breakfast reduced and control blood glucose fluctuations throughout the day. Conducting exercises during night time can intensify heart rate especially in the first 3 hours approaching bedtime (Myllymaki et al., 2011) and 
there is a strong correlation between circadian rhythms with physical activity on the heart (Wang, 2017). The sleep quality is improved if exercise done in the morning than in the night (Andriana \& Ashadi, 2019). Therefore, there needs to be a study done in determining the effective time to exercise.

Circadian rhythm is a change of physical, mental, and behavioral which follows a daily cycle (daynight), including the production of cortisol, melatonin, corticotropin-releasing- factor (CRF) and adrenocorticotropic hormone (ACTH). Suprachiasmatic Nucleus (SCN) or the body's master clock located in the brain can control certain production of hormone and substance in the body through the light (day- night) that enters the eyes then through the optic nerve and finally transfers it to a part of the brain called hypothalamus (NIGMS, 2017). The existence of this day-night cycle makes a high level of $\mathrm{CRF}, \mathrm{ACTH}$ and cortisol secretion in the morning and low level at night. Cortisol contribute in regulating carbohydrates, including the process of glucose formation through gluconeogenesis, reducing the use of glucose by cells, affect the transportation of fatty acids in the body (Guyton \& Hall, 2015) and eventually increase plasma glucose levels (Qaid \& Abdelrahman, 2016). Apart from improving body condition, exercise can also affect the metabolism of blood glucose regulation. If it is not controlled, glucose could be a leading factor in the emergence of several diseases including obesity, diabetes mellitus, and even cardiovascular disease. Through several steps, exercise is a way to regulate blood glucose levels by muscle contraction (Lieberman \& Marks, 2012). Exercise affects patients with type 2 diabetes mellitus (Figueira, 2013) and type 1 (Colberg et al., 2013) in reducing blood glucose acutely.

\section{OBJECTIVE}

Due to the fact that there is still a lack of data regarding the effective time to exercise and zero study reveal the difference in the effect of exercise in the morning and evening time acutely on blood glucose levels, the purpose of this study was to prove and find out the comparison of changes in blood glucose levels before and after moderate intensity exercise in morning and evening. The specific objectives of this study were to determine the blood glucose levels before and after moderate intensity exercise acutely and to compare changes in blood glucose levels before and after a moderate intensity exercise in morning and evening.

\section{MATERIALS AND METHODS}

The study design, methods and procedures had been approved (No.224/EC/KEPK/FKUA/2018) by the Medical Research Ethic Committee of Faculty of Medicine, Universitas Airlangga. This was an experimental pretest-posttest group design research with 2 experimental groups, morning and evening groups. This research was conducted in January 2019 - June 2019 in the Laboratory/Department of Physiology and Biochemistry, Faculty of Medicine, Universitas Airlangga, Surabaya, East Java.

Thirty-four healthy men were divided into 2 groups, morning $(n=17)$ and evening $(n=17)$. The sampling technique that were used was purposive sampling technique, which had criteria of age of 1722 years old, Body Mass Index of $18.5-22.9 \mathrm{~kg} / \mathrm{m}^{2}$ (normal Asia Pacific), willing, and taking into account that the subjects had no symptoms of heart disease, disorders of the bone and joints, and not taking any medications for blood pressure or heart problems that might have affected the ability to participate in the research. Subjects drew a lottery to determine the group whether they were in the morning group (8:00 in the morning) or evening group (20:00). There were 17 subjects who performed moderate intensity exercise in the morning and 17 subjects that performed moderate intensity exercise at evening.

In the morning group, subjects were asked to fast and was allowed only to drink water from 23:00 at night and in the evening group, subjects were asked to fast from 12:00 at noon. All of the subject drank a glass of tea with $2 \frac{1}{2}$ teaspoon of sugar 2 hours before doing moderate intensity exercise. Capillary blood was taken from both group before doing the exercise to determine the 2-hour post prandial blood glucose pre-test using Easy Touch Point of Care Testing. Subjects performed moderate intensity exercise using Ergocycle at 55-70\% of the maximum heart rate limit, measured using Polar Heart Rate, with a total duration of 40 minutes (30 minutes +10 minutes warming up and cooling down). After exercising, capillary blood from both group was taken again to determine the post-test blood glucose level immediately after exercise or acutely. Furthermore, all data were statistically 
analyzed and interpreted using statistical program. and SPSS 22 using the Chi-square and also t-test with the significance level of $\mathrm{p}<0.05$.

\section{RESULTS}

All data were shown in mean \pm standard deviation. Based on the Independent $\mathrm{T}$ Test results in Table 1 below it can be seen that the mean age of the morning group was $19.53 \pm 1.23$ years and the mean age of the evening group was $18.94 \pm 1.43$ years. This shows that the mean age of the morning group was 0.59 years higher than the mean age of the evening group, but there was no significant difference $(\mathrm{p}=0.209)$. The mean BMI of the morning group was $20.6 \pm 1.15 \mathrm{~kg} / \mathrm{m}^{2}$ and the mean BMI of the evening group was $20.1 \pm 1.09 \mathrm{~kg} / \mathrm{m}^{2}$. There was no significant difference $(\mathrm{p}=0.220)$ between the two groups. The results showed that the subjects BMI did not affect the results of the study and were all in the normal category of BMI Asia Pacific.

Table 1. Characteristics of Subjects

\begin{tabular}{lccc}
\hline Variable & Group & $\mathrm{N}$ & Mean $p$ \\
\hline Age & Morning & 17 & $19.53 \pm 1.23$ \\
& Evening & 17 & $18.94 \pm 1.435$ \\
BMI & Morning & 17 & $20.6746 \pm 1.15327$ \\
& Evening & 17 & $20.1825 \pm 1.09251$ \\
\hline \multicolumn{2}{l}{ BMI: Body Mass Index } & & \\
p $>0.05=$ not significant & &
\end{tabular}

Shapiro-Wilk normality test for both group (morning and evening) on the variable of blood glucose levels before and after moderate intensity exercise and the decrease in blood glucose levels had normal distribution ( $\mathrm{p}>0.05)$.

Table 2 showed that the mean blood glucose levels before exercise in the morning group was $86.24 \pm 7.72 \mathrm{mg} / \mathrm{dL}$ and the mean blood glucose level immediately after exercise was $77.88 \pm 9.49 \mathrm{mg} / \mathrm{dL}$. In the evening group it was shown that the mean blood glucose levels before exercise was $85.94 \pm 6.81$ $\mathrm{mg} / \mathrm{dL}$ and the mean blood glucose levels immediately after exercise was $79.65 \pm 9.99 \mathrm{mg} / \mathrm{dL}$. There were significant differences between before and immediately after exercise in both morning group $(\mathrm{p}=0.002)$ and evening group $(\mathrm{p}=0.021)$ based on the results of the paired T Test.

Table 2. Blood glucose levels before and after exercise in morning and evening.

\begin{tabular}{clcc}
\hline Group & Variable & Mean & $P$ \\
\hline Morning & Pre & $86.24 \pm 7.62$ & \\
& Post & $77.88 \pm 9.49$ & $0.002 *$ \\
Evening & Pre & $85.94 \pm 6.81$ & \\
& Post & $79.65 \pm 9.29$ & $0.021^{*}$ \\
\hline *p $<0.05=$ significant & \multicolumn{2}{c}{ Post = Acutely after exercise } \\
& & \multicolumn{2}{c}{ Pre = Before exercise }
\end{tabular}

Table 3 shows the results of the Independent $\mathrm{T}$ Test that there is no significant difference $(\mathrm{p}=0.538)$ between changes in blood glucose levels before and after moderate intensity exercise in the morning and evening group. The mean decrease in the morning group was $-8.35 \pm 9.165 \mathrm{mg} / \mathrm{dL}$ while in the evening group was $-6.29 \pm 10.104 \mathrm{mg} / \mathrm{dL}$. This shows that the decrease in blood glucose levels in the morning group is $2.06 \mathrm{mg} / \mathrm{dL}$ higher than in the evening group, although it does not differ significantly.

Table 3. Mean decrease in blood glucose levels before and after exercise in the morning and evening groups

\begin{tabular}{cccc}
\hline Variable & Group & Mean & $\mathrm{P}$ \\
\hline deltaglucose & Morning & $-8.35 \pm 9.165$ & 0.538 \\
& Evening & $-6.29 \pm 10.104$ & \\
\hline $\mathrm{p}>0.05=$ not significant & &
\end{tabular}




\section{DISCUSSION}

Cortisol hormone is regulated by excitation of the hypothalamus through different types of stress. Stress activates the body to cause a rapid release of cortisol, then it initiates a series of metabolic effects aimed at reducing the harmful effect of the stressful state. CRF, ACTH, and cortisol secretion levels are high in the morning but low at night, plasma cortisol levels range between $20 \mu \mathrm{g} / \mathrm{dL}$ per hour before morning time and low about $5 \mu \mathrm{g} / \mathrm{dL}$ around midnight. This is the result of the 24-hour day cycle causing changes to cortisol secretion from the hypothalamus throughout the day.

Metabolic effects of cortisol and glucocorticoids are the formation of carbohydrates from protein and other substances by the liver and can increase the rate of gluconeogenesis 6 to 10 times. Cortisol increase enzymes needed to convert amino acids into glucose in liver cells, as well as being an antagonist of the effects of insulin by increasing gluconeogenesis in the liver. One effect of cortisol is reducing GLUT 4 translocation into cell membranes, especially in skeletal muscle cells, which causes the body to become insulin resistance. High glucocorticoid levels can reduce sensitivity to many tissues, especially skeletal muscles and adipose tissue. A significant increase in blood glucose concentration (50 percent or more above normal) is called adrenal diabetes (Guyton and Hall, 2015). The mean blood glucose level before exercise in the morning group was higher than in the evening group, but not significantly. According to research conducted by Fernandes et al. (2014) plasma glucose levels at night are higher than in the morning with the hypothesis that an increase in the hormone insulin and decreased concentration of growth hormone $(\mathrm{GH})$ in the morning cause a decrease in plasma glucose levels.

Blood glucose level were significantly decrease between before and after moderate intensity exercise for both morning and evening group acutely. It is due to due to increase GLUT-4 muscle mRNA immediately after exercise (Richter \& Hargreaves, 2013) and also exercise causes muscles to be more active and sensitive to insulin, thus muscles can utilize more glucose which then lead to a decrease in glucose level (Stanford \& Goodyear, 2014). In line with a research done by Savikj et al. (2018), high intensity interval training in the afternoon is more effective in improving (reducing) blood glucose levels than in the morning. This can be due to the strength of the human skeletal muscle and mitochondrial function peaks in the afternoon, showing the circadian rhythm of oxidative metabolism.

Conversely, Savikj et al. (2018) research stated that some high intensity interval training in the morning has an acute effect of increasing blood glucose level after exercise. It is supported by Gomez et al. (2015) where there are fewer hypoglycemic events if exercise performed in the morning. Exercising in the morning increases metabolic control the for next day and keeps patients in the euglycemic range for longer periods. This could be due to higher norepinephrine levels after exercise, so glucose levels after exercise in the morning are higher when compared to the night (Fernandes et al., 2014).

Comparison of changes in blood glucose level before and after moderate intensity exercise between morning and evening group showed that there was no significant difference. Similar to the result, a study done by Fernandes et al. (2014) proved that the difference of time in exercise was not significant.

Factors that affect blood glucose levels during exercise include last meal time, duration and intensity of the exercise. Time of last intake of food or drinks before exercise was proven to affect glucose changes by Colberg et al. (2013), showed that exercising 1 or 2 hours after the last intake decreases more blood glucose levels rather than 30 minutes after the last intake in patients with type 1 diabetes mellitus. Duration of the exercise will reduce more blood glucose level if it is longer in time, showed in patients with type 1 diabetes (Colberg, 2013). Lastly, the exercise intensity had a different effect on blood glucose with different intensity. In the study conducted by Atsari, Susanto \& Argarini (2016), it showed that moderate intensity 
continuous training reduced glucose levels much more than high intensity continuous training.

\section{CONCLUSION}

Moderate intensity exercise significantly decreases blood glucose levels in the morning and evening groups, due to an increase in GLUT-4 contracting muscles. There were no differences concerning the effect on blood glucose changes between performing exercise in the morning or in the evening. This could be due to cortisol hormone affecting blood glucose levels in morning and evening, but could be stabilized by insulin and norepinephrine in the body. However, further research is needed to better understand the underlying mechanisms.

\section{REFERENCES}

Andriana, L.M., Ashadi, K., 2019. Perbandingan dua jenis olahraga pada pagi dan malam hari terhadap kualitas tidur [Comparison of two exercises in morning and evening on sleep quality]. Jurnal SPORTIF: Jurnal Penelitian Pembelajaran, 5(1): 98-112.

Atsari, N., Susanto, H.. Argarini, R., 2016. Perbandingan latihan kontinu intensitas sedang dan latihan interval intensitas tinggi terhadap kontrol glukosa darah [Comparison of moderate intensity continuous exercise and high intensity interval exercise on blood glucose]. Majalah Kedokteran Bandung, 48(4): 194-9.

Colberg, S.R., Hernandez, M.J., Shahzad, F., 2013. Blood glucose responses to type, intensity, duration, and timing of exercise. Diabetes Care, 36(10): e177.

Fernandes, A., Lopes-Silva, J., Bertuzzi, R., Casarini, D., Arita, D., Bishop, D., Lima-Silva, A., 2014. Effect of time of day on performance, hormonal and metabolic response during a 1000-m cycling time trial. Plos ONE, 9(10): e109954.

Figueira, F., Umpierre, D., Casali, K., Tetelbom, P., Henn, N., Ribeiro, J., Schaan, B., 2013. aerobic and combined exercise sessions reduce glucose variability in Type 2 Diabetes: Crossover randomized trial. PLoS ONE, 8(3), p.e57733.

Gomez, A., Gomez, C., Aschner, P., Veloza, A., Muñoz, O., Rubio, C., Vallejo, S., 2015. Effects of performing morning versus afternoon exercise on glycemic control and hypoglycemia frequency in type 1 diabetes patients on sensor- augmented insulin pump therapy. Journal of Diabetes Science and Technology, 9(3):.619-24.

Hall, J., Guyton, A., 2015. Guyton and Hall textbook of medical physiology. 13th ed. Philadelphia: Elsevier, 976- 977.

Lieberman, M., Marks, A. 2012. Marks' basic medical biochemistry. 4th ed. Philadelphia: Lippincott Williams and Wilkins. 333

Myllymäki, T., Kyröläinen, H., Savolainen, K., Hokka, L., Jakonen, R., Juuti, T. et al., 2011. Effects of vigorous late- night exercise on sleep quality and cardiac autonomic activity. Journal of Sleep Research, 20(1pt2): 146-53.

Qaid, M., Abdelrahman, M., 2016. Role of insulin and other related hormones in energy metabolis a review. Cogent Food \& Agriculture, 2(1).

Richter, E., Hargreaves, M., 2013. Exercise, GLUT4, and skeletal muscle glucose uptake. Physiological Reviews, 93(3): 993-1017.

Savikj, M., Gabriel, B., Alm, P., Smith, J., Caidahl, K., Björnholm, M. et al., 2018. Afternoon exercise is more efficacious than morning exercise at improving blood glucose levels in individuals with type 2 diabetes: a randomised crossover trial. Diabetologia, 62(2): 233-7.

Stanford, K., Goodyear, L., 2014. Exercise and type 2 diabetes: molecular mechanisms regulating glucose uptake in skeletal muscle. Advances in Physiology Education, 38(4): 308-14.

Wang, C.Y., 2017. Circadian rhythm, exercise, and heart. Acta Cardiologica Sinica, 33(5): 539-41.

World Health Organization. 2018. Global strategy on diet, physical activity and health. Downloaded from http://www.who.int/dietphysicalactivit y/pa/en/.

World Health Organization. (n.d.). Physical activity. Downloaded 26 April 2018 from http://www. who.int/topics/physical_ac tivity/en/. 
Zheng, X., Qi, Y., Bi, L., Shi, W., Zhang, Y., Zhao, D., Hu, S., Li, M. and Li, Q., 2020. Effects of exercise on blood glucose and glycemic variability in Type 2 diabetic patients with dawn phenomenon. BioMed Research International, 1-6. 